\title{
Photothermal Deflection Spectroscopy Study of Nanocrystalline Si (nc-Si) Thin Films Deposited on Porous Aluminum with PECVD
}

\author{
S. Ktifa, ${ }^{1}$ M. Ghrib, ${ }^{2}$ F. Saadallah, ${ }^{1}$ H. Ezzaouia, ${ }^{2}$ and N. Yacoubi ${ }^{1}$ \\ ${ }^{1}$ Photothermal Laboratory, Nabeul, Tunisia \\ ${ }^{2}$ Photovoltaic Laboratory, Research and Technology Centre of Energy, Borj-Cedria Science and Technology Park, BP 95, \\ 2050 Hammam-Lif, Tunisia
}

Correspondence should be addressed to F. Saadallah, faycel1@yahoo.fr

Received 15 December 2011; Revised 12 February 2012; Accepted 13 February 2012

Academic Editor: Bhushan Sopori

Copyright () 2012 S. Ktifa et al. This is an open access article distributed under the Creative Commons Attribution License, which permits unrestricted use, distribution, and reproduction in any medium, provided the original work is properly cited.

\begin{abstract}
We have studied the optical properties of nanocrystalline silicon (nc-Si) film deposited by plasma enhancement chemical vapor deposition (PECVD) on porous aluminum structure using, respectively, the Photothermal Deflection Spectroscopy (PDS) and Photoluminescence (PL). The aim of this work is to investigate the influence of anodisation current on the optical properties of the porous aluminum silicon layers (PASL). The morphology characterization studied by atomic force microscopy (AFM) technique has shown that the grain size of (nc-Si) increases with the anodisation current. However, a band gap shift of the energy gap was observed.
\end{abstract}

\section{Introduction}

Porous anodic alumina films are an interesting material [1] for nanotechnology applications because of their unusual properties compared to the bulk counterparts [2]. Many works have been published relative to the deposition of porous aluminum films [3, 4]. Different methods of film growth on the surface of the porous matrix layer were used, as for example reactive sputtering [5] and low pressure metal-organic chemical vapor deposition [6].

In this work we demonstrate the capability to grow porous aluminum layers (PAL) by a simple electrochemical anodisation method. The anodizing process was done by varying the anodizing voltage between 200 to $400 \mathrm{mV}$. Crystalline silicon films are deposited on the PAL by a PECVD technique. Photothermal deflection spectroscopy (PDS) is used to determine the optical absorption spectrum and gap energy by comparing the experimental amplitude of the photothermal signal to the corresponding theoretical one. PL and PDS are used in order to study the influence of anodic current on optical properties of our samples. For this purpose, absorption spectrum, gap energies are measured.
The optical properties of the deposited films are correlated to the porous aluminum and nc-Si films morphologie.

\section{Film Preparation}

High-purity aluminum foil (99.997\%), $0.25 \mathrm{~mm}$ thick, was used as a starting material. The cleaned samples were anodized during $25 \mathrm{~min}$ in a solution of diluted sulfuric acid with $66.66 \% \mathrm{H}_{2} \mathrm{SO}_{4}$ and $33.33 \% \mathrm{H}_{2} \mathrm{O}_{2}$ at room temperature and with five different anodization currents $(200 \mathrm{~mA}$, $250 \mathrm{~mA}, 300 \mathrm{~mA}, 350 \mathrm{~mA}$, and $400 \mathrm{~mA}$ ). On the surface, ncSi films were deposited by PECVD technique [7] at $50^{\circ} \mathrm{C}$ using a gas mixture of silane and $\mathrm{H}_{2}$ at a total pressure of 0.5 mTorr.

\section{AFM Characterization}

The surface morphology of the films was examined by atomic force microscopies. Figure 1 shows AFM images of porous $\mathrm{Al}$ filled of nc-Si and obtained with different anodisation currents varying from $200 \mathrm{~mA}$ to $400 \mathrm{~mA}$. The surface shows 


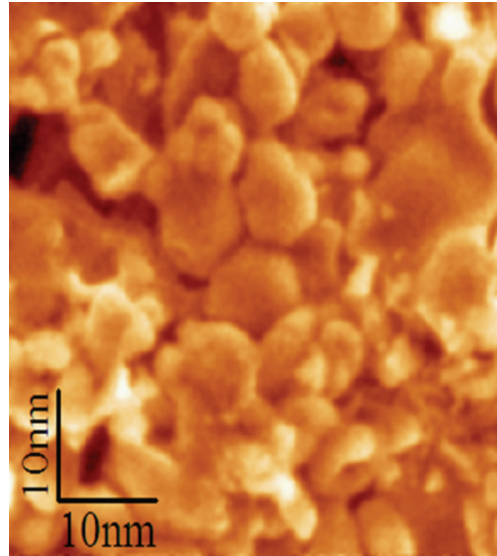

(a)

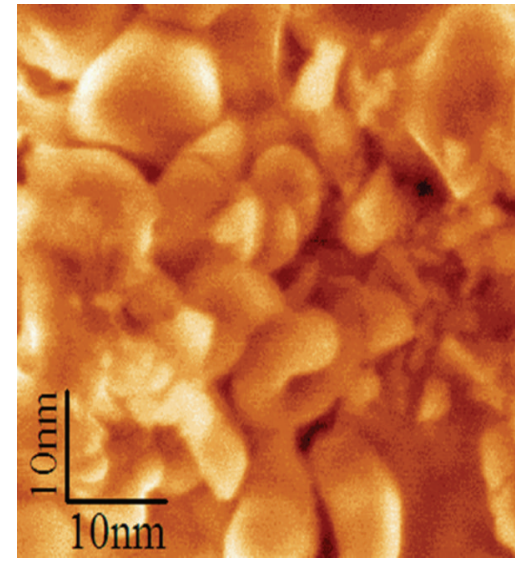

(b)

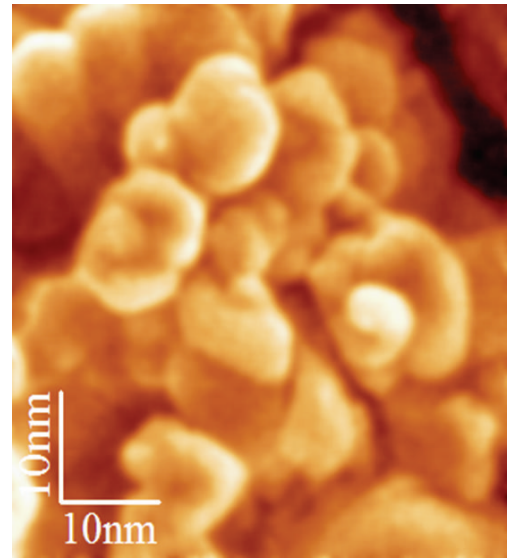

(c)

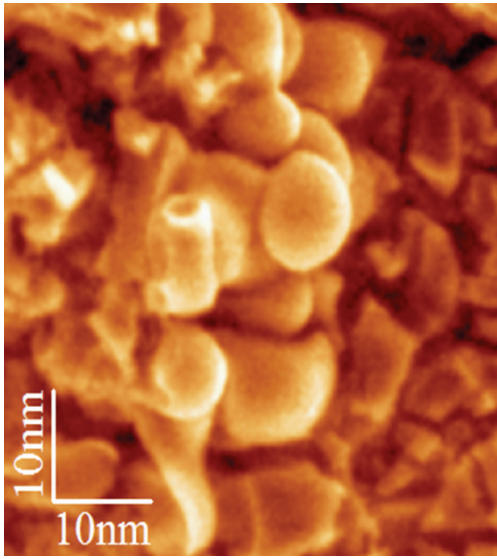

(d)

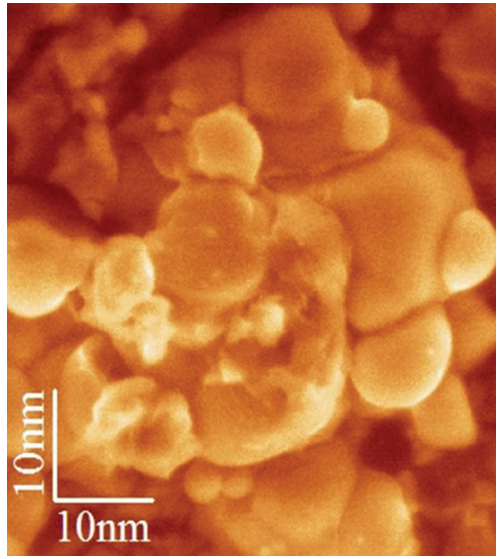

(e)

FIGURE 1: AFM images of silicon deposited on porous aluminum layer (PAL) as a function the anodisation current.

spherical domes with an average size (as estimated from the AFM images), varying approximately from 12 to $15 \mathrm{~nm}$ as a function of the anodisation current.

\section{Optical Characterization}

4.1. Photoluminescence. The PL properties were measured using an Ar laser $(\lambda=364 \mathrm{~nm})$ and detected by a cooled GaInAs detector with a standard technique using a lock-in.

Figure 2(a) shows the PL spectrum of the nc-Si layer. The PL emission lies in the orange region of the visible spectral range. The PL band peak position varies from $616 \mathrm{~nm}$ to $624 \mathrm{~nm}$ (2 and $1.98 \mathrm{eV}$, resp.) as $I_{a}$ increases from 200 to $400 \mathrm{~mA}$. This observed PL does not seem to have its origin only from silicon nanocrystals embedded in the porous aluminum matrix, as proposed by Ong and Zhu [8] but it is due to the contributions of the two materials ( $\mathrm{Si}$ incorporated in PAL). To assure that these peaks come from the nc-Si films, we have measured the PL of porous Al (without nc-Si). As shown in Figure 2(b), the PL peak originates from the PAL that is located at $430 \mathrm{~nm}(2.8 \mathrm{eV})$ far from the nc-Si ones. The PL peak position represents a blue shift as the nc-Si size decrease. This effect could be explained by the increase of $\mathrm{Si}-\mathrm{O} / \mathrm{Si}-\mathrm{H}$ surface bond ratio [9]

4.2. Photothermal Measurements. The photothermal deflection spectral measurements have been used for investigating optical properties of semiconductors. The great advantage of the PDS is that it is a direct monitor of the nonradiative recombination processes of photo-excited electrons in a semiconductor.

The experimental setup has been described in detail in [10]. When a sample (Figure 1) is irradiated with modulated and monochromatic beam radiation, the absorbed energy is converted into heat through different relaxation processes. The generated thermal wave diffuses in the material and in the surrounding fluid $\left(\mathrm{CCl}_{4}\right)$. The temperature variations in the fluid lead to a refractive index gradient causing the deflection of a probe laser beam ( $\mathrm{He}-\mathrm{Ne} 4 \mathrm{~mW}$ ) skimming the sample surface. This deflection is detected by a position photosensor linked to a lock in amplifier. The obtained photothermal signal has two compounds: amplitude and phase. 


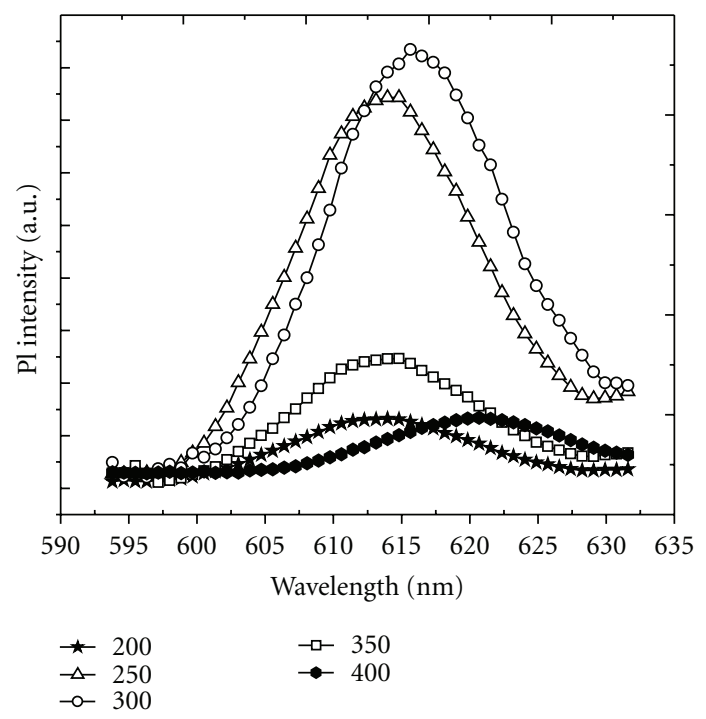

(a)

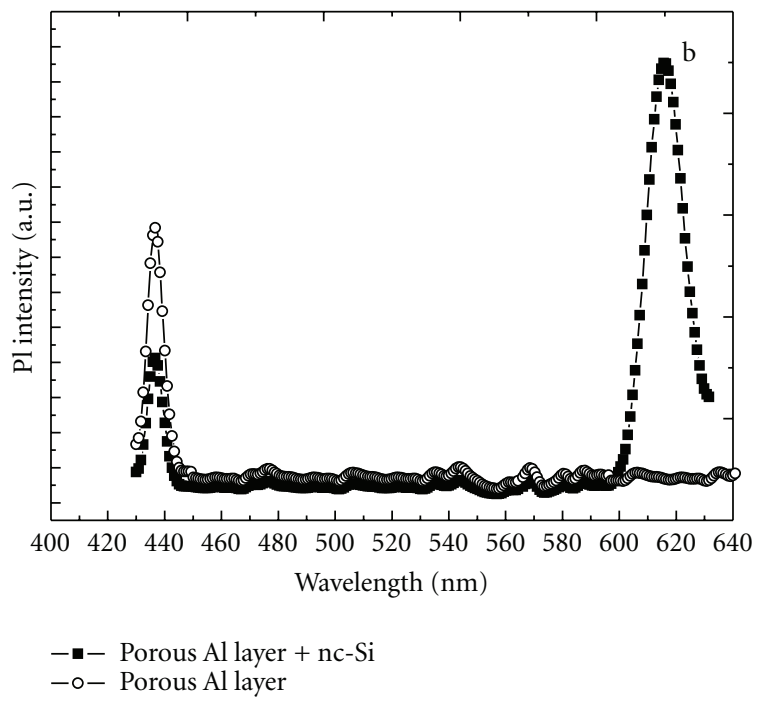

(b)

Figure 2: (a) PL spectra of the nc-Si layer as a function of $I_{a}$ and (b) typical PL spectrum of nc-Si films compared to PL response of the porous Al layer.

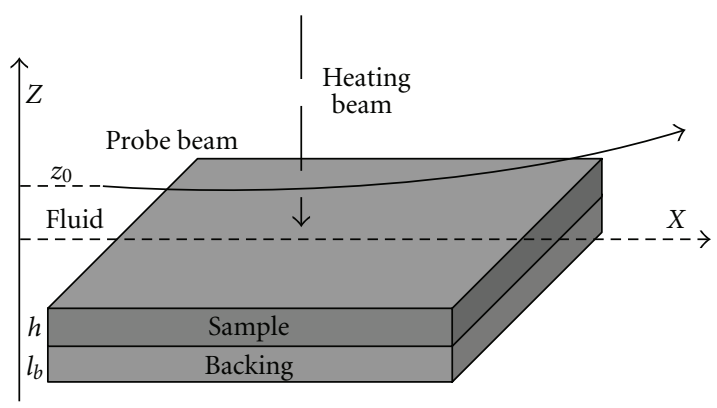

Figure 3: Schema of photothermal deflection principle.

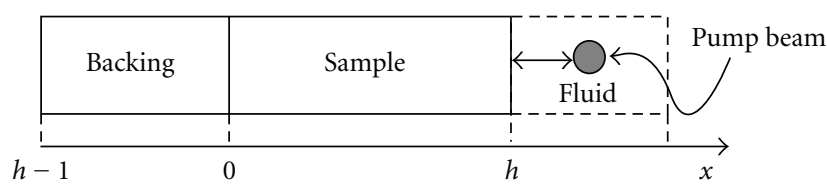

FIgUre 4: Schema of the PASL sample.

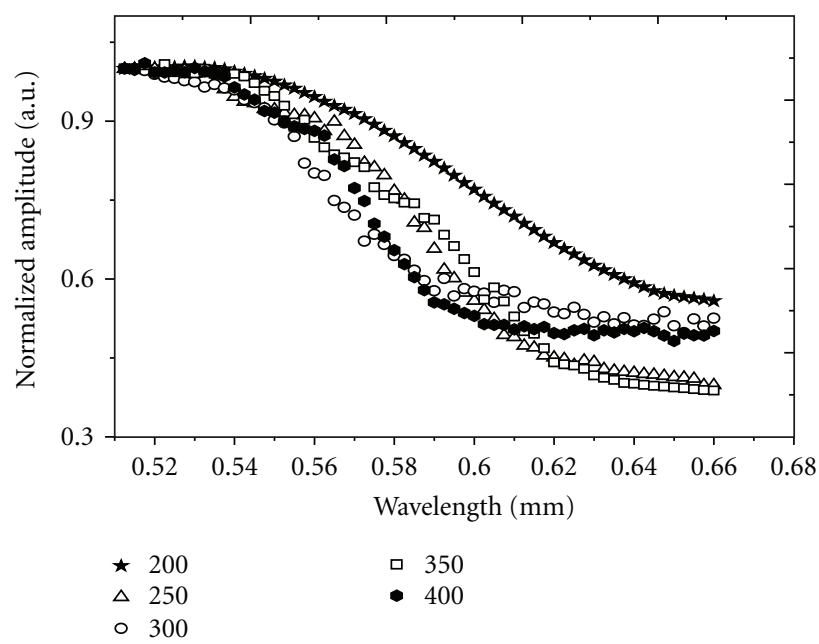

FIGURE 5: Normalized amplitude obtained with different PASL samples.

The principle of this technique is shown in Figure 3. The probe beam deflection is given by [11]: $\Psi=L / n(d n / d T) \sigma_{f} T_{0}$ where $n$ is the fluid refractive index, $x_{0}$ is the distance between probe beam axis and the sample surface, and $L$ is the sample length. $\sigma_{f}=(1+j) / \mu_{f}, \mu_{f}=\sqrt{D_{f} / \pi F}$ is thermal diffusion length in the fluid, $D_{f}$ the thermal diffusivity, and $F$ is the modulation frequency of the heating beam. We notice that the deflection is proportional to the complex temperature expression $T_{0}$ at the sample surface. This temperature $T_{0}$ is calculated by solving the one-dimensional heat equation in the different media sample, backing, and the surrounding fluid (Figure 4):

$$
\begin{array}{lr}
\frac{\partial T_{f}}{\partial x^{2}}=\frac{1}{D_{f}} \frac{\partial T_{f}}{\partial t} \quad \text { for } x>0, & \\
\frac{\partial T_{e}}{\partial x^{2}}=\frac{1}{D_{e}} \frac{\partial T_{b}}{\partial t}-A \exp (\alpha x)(1+\exp (j w t)), \\
\text { for }-h<x<0, \\
\frac{\partial T_{b}}{\partial x^{2}}=\frac{1}{D_{b}} \frac{\partial T_{b}}{\partial t}, \quad \text { for }-h-l_{b}<x<-h .
\end{array}
$$

These equations are solved while taking into account of the boundary conditions at different interfaces. The obtained surface temperature $T_{0}$ is given by

$$
T_{0}=\frac{\alpha I_{0}}{2 K_{e}\left(\alpha^{2}-\sigma^{2}\right)}\left[\frac{(r-1)(b+1) \exp \left(\sigma_{e} h\right)-(r+1)(b-1) \exp \left(-\sigma_{e} h\right)+2(b-r) \exp (-\alpha h)}{(g+1)(b+1) \exp \left(\sigma_{e} h\right)-(g-1)(b-1) \exp \left(-\sigma_{e} h\right)}\right] .
$$




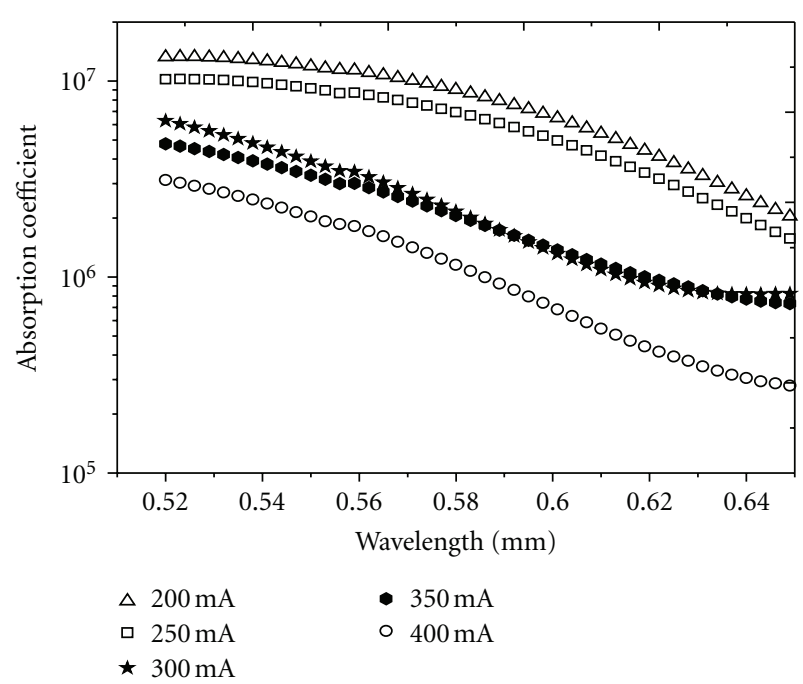

Figure 6: Optical absorption spectra of PASL samples.

TABLE 1: Evolution of the bandgap energies.

\begin{tabular}{lccc}
\hline PASL Sample & $\begin{array}{c}\text { Anodisation current } \\
I_{a}(\mathrm{~mA})\end{array}$ & $\begin{array}{c}E_{g}(\mathrm{eV}) \\
\text { PDS }\end{array}$ & $\begin{array}{c}E_{g}(\mathrm{eV}) \\
\text { PL }\end{array}$ \\
\hline A & 200 & 2.2 & 2.2 \\
B & 250 & 2 & 1.99 \\
C & 300 & 2.01 & 1.9 \\
D & 350 & 1.95 & 1.98 \\
E & 400 & 1.93 & 1.97 \\
\hline
\end{tabular}

Thermal and optical parameters that appear in the above expression are given in [12].

4.2.1. Near Gap Absorption Spectrum. Figure 5 shows the obtained experimental curves of the normalized amplitude for the studied samples: nanocrystalline Si (nc-Si) thin films deposited on porous aluminum by plasma-enhanced chemical vapor deposition as a function the anodisation current. $200,250,300,350$, and $400 \mathrm{~mA}$. The amplitude shows two saturations zones corresponding, respectively, to high and low optical absorption coefficient. For energy higher than the gap energy, the sample is optically opaque (maximum amplitude) and became more and more transparent when the energy decreases (minimum amplitude). We notice that in the subband gap region, the amplitude saturates at different minimum values for each sample.

The comparison of experimental curves of amplitude versus wavelength to theoretical amplitude versus absorption coefficient permits to obtain the optical absorption spectrum for the samples shown on Figure 6. We remark that the lessanodized sample has a relative higher absorption coefficient in the transparency zone.

4.2.2. Determination of the Gap Energies. In order to obtain the gap energy $E_{g}$ from optical spectra, we have used the Tauc method [13, 14]. For energies $E=h v$ higher than $E_{g}$, the quantity $(\alpha E)^{n}$ should have linear variations with $E$,

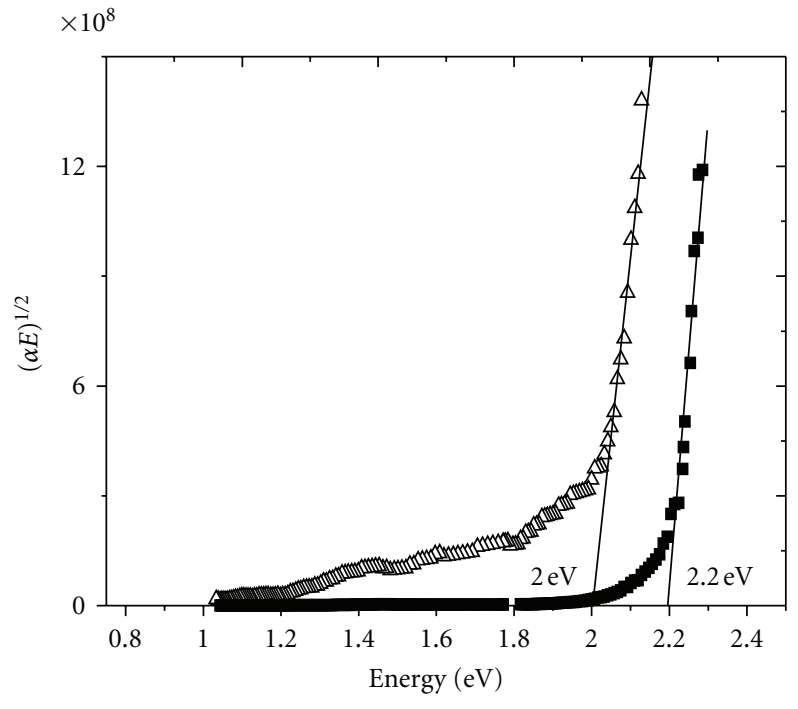
$\triangle 200$
- 250

(a)

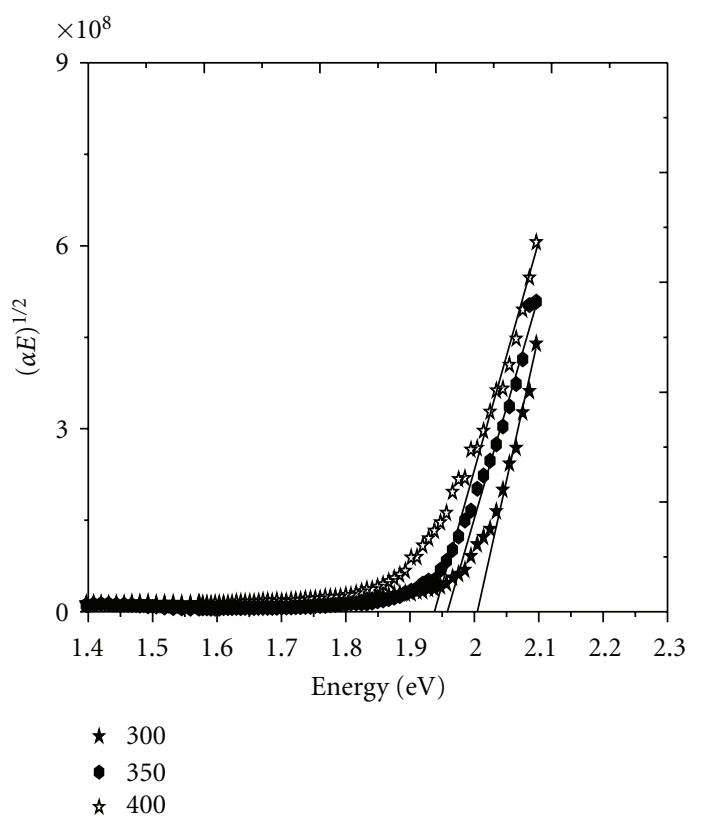

(b)

FIgURe 7: $(\alpha E)^{1 / 2}$ versus energy $E$ near the bandgap for the PASL samples.

following the Tauc law: $(\alpha E)^{n}=\beta\left(E-E_{g}\right)$ where $\alpha$ is the absorption coefficient and $\beta$ is the slope of the curve. For indirect bandgap semiconductor such as nanocrystalline $\mathrm{Si}$ (nc-Si) thin films deposited on porous aluminum: $n=1 / 2$. The curves of $(\alpha E)^{1 / 2}$ versus $E$ are shown in Figures $7(\mathrm{a})$ and $7(\mathrm{~b})$. The obtained gap energy $E_{g}$ values are reported in Table 1. We notice a bandgap shift of about $24 \mathrm{mev}$. The energy bandgap decreases with anodisation current and varies from 2.2 to $1.9 \mathrm{eV}$ as $I_{a}$ varies from 200 to $400 \mathrm{~mA}$, 
respectively (Table 1 ). The obtained value of $E_{g}$ agrees with gap energies measured by other authors [15].

Comparison between the various bandgap shows that the optical absorption properties are significantly affected by particle size of the nc-Si films. The fact that these energies are high than the expected ones (for nanosized $\mathrm{Si}$ crystal) could be explained by the contribution of alumina in the absorption spectra. Alumina has in fact a high band gap energy $(\approx 3.2 \mathrm{eV})$ [16] compared to silicon. The effect could be also attributed to the presence of particles with very small size (quantum confinement). In Table 1, the gap energies measured with photoluminescence spectra and photothermal deflection has been compared for different anodized levels. We notice that the $E_{g}$ is slightly higher than the real gap energy determined by photothermal deflection, because it corresponds to the radiative transition.

\section{Conclusion}

In this work, nanocrystal silicon thin films were deposited by PECVD technique on a porous aluminum substrate prepared with different anodizations currents. Optical absorption spectrum, and gap energy are measured and analyzed using the PL and PDS techniques. A bandgap shift induced by the anodisation current is detected. We found a correlation between the particle size and the gap energy.

\section{References}

[1] L. F. Marsal, L. Vojkuvka, P. Formentin, J. Pallarés, and J. Ferré-Borrull, "Fabrication and optical characterization of nanoporous alumina films annealed at different temperatures," Optical Materials, vol. 31, no. 6, pp. 860-864, 2009.

[2] F. Wang, H. Huang, and S. Yang, "Synthesis of ceramic nanotubes using AAO templates," Journal of the European Ceramic Society, vol. 29, no. 8, pp. 1387-1391, 2009.

[3] D. Auvergne, J. Camassel, and H. Mathieu, "Band-gap shrinkage of semiconductors," Physical Review B, vol. 11, no. 6, pp. 2251-2259, 1975.

[4] G. E. Thompson, "Porous anodic alumina: fabrication, characterization and applications," Thin Solid Films, vol. 297, no. 1-2, pp. 192-201, 1997.

[5] Y. Zhao, Y. Qian, W. Yu, and Z. Chen, "Surface roughness of alumina films deposited by reactive r.f. sputtering," Thin Solid Films, vol. 286, no. 1-2, pp. 45-48, 1996.

[6] W. Koh, S. J. Ku, and Y. Kim, "Chemical vapor deposition of Al2O3 films using highly volatile single sources," Thin Solid Films, vol. 304, no. 1-2, pp. 222-224, 1997.

[7] J. J. Simonne, "State of the art in InP MIS technology," in Proceedings of the International Conference (INFOS '83), pp. 63-70, Eindhoven, The Netherlands, 1983.

[8] P. P. Ong and Y. Zhu, "Strong photoluminescence with fine structures from sandwich-structured films of silicon nanoparticles embedded in $\mathrm{Al}_{2} \mathrm{O}_{3}$ matrices," Physica E, vol. 15, no. 3, pp. 118-123, 2002.

[9] H. C. Chen, W. Wang, K. N. Manjularni, L. C. Snyder, and X. L. Zheng, "Heating laser irradiation and passivation study on the light-emitting porous silicon," Materials Research Society Symposium Proceedings, vol. 256, pp. 197-202, 1992.

[10] F. Saadallah, N. Yacoubi, F. Genty, and C. Alibert, "Investigation of thermal and optical properties of distributed Bragg reflectors by photothermal deflection spectroscopy," Applied Optics, vol. 41, no. 36, pp. 7561-7568, 2002.

[11] S. Abroug, F. Saadallah, and N. Yacoubi, "Determination of doping effects on $\mathrm{Si}$ and GaAs bulk samples properties by photothermal investigations," Physica B, vol. 400, no. 1-2, pp. 163-167, 2007.

[12] "Photothermal and photoacoustic spectroscopy measurement," in Handbook of Optical Constants, vol. 3, p. 88, 1998.

[13] S. E. Aw, H. S. Tan, and C. K. Ong, "Optical absorption measurements of band-gap shrinkage in moderately and heavily doped silicon," Journal of Physics: Condensed Matter, vol. 3, no. 42, article no. 016, pp. 8213-8223, 1991.

[14] A. Chandola, R. Pino, and P. S. Dutta, "Below bandgap optical absorption in tellurium-doped GaSb," Semiconductor Science and Technology, vol. 20, no. 8, pp. 886-893, 2005.

[15] M. Ghrib, M. Gaidi, T. Ghrib, N. Khedher, M. Ben Salam, and H. Ezzaouia, "Morphological and optical properties changes in nanocrystalline $\mathrm{Si}$ (nc-Si) deposited on porous aluminum nanostructures by plasma enhanced chemical vapor deposition for Solar energy applications," Applied Surface Science, vol. 257, no. 21, pp. 9129-9134, 2011.

[16] I. Costina and R. Franchy, "Band gap of amorphous and wellordered Al2O3 on Ni3Al(100)," Applied Physics Letters, vol. 78, no. 26, pp. 4139-4141, 2001. 


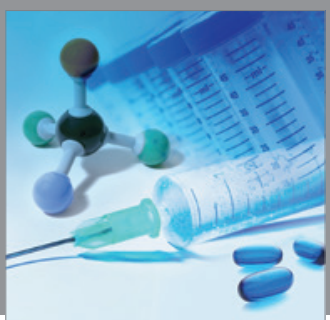

International Journal of

Medicinal Chemistry

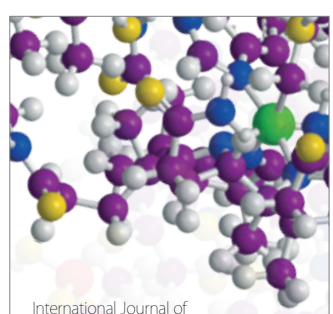

Carbohydrate Chemistry

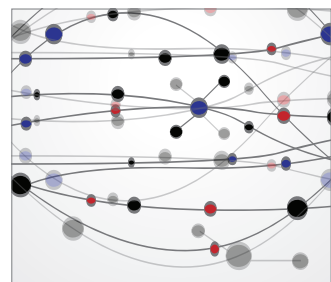

The Scientific World Journal
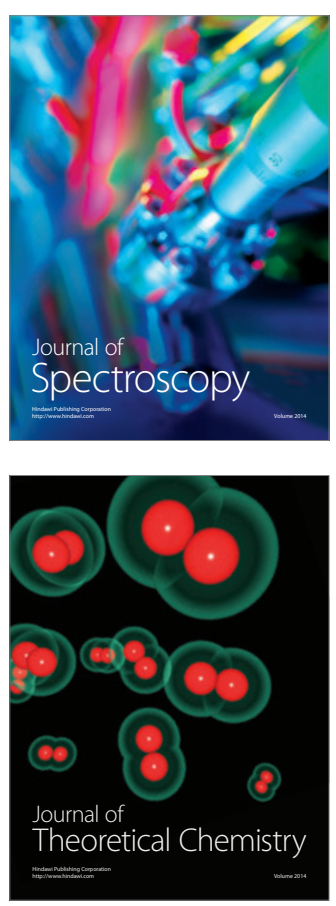
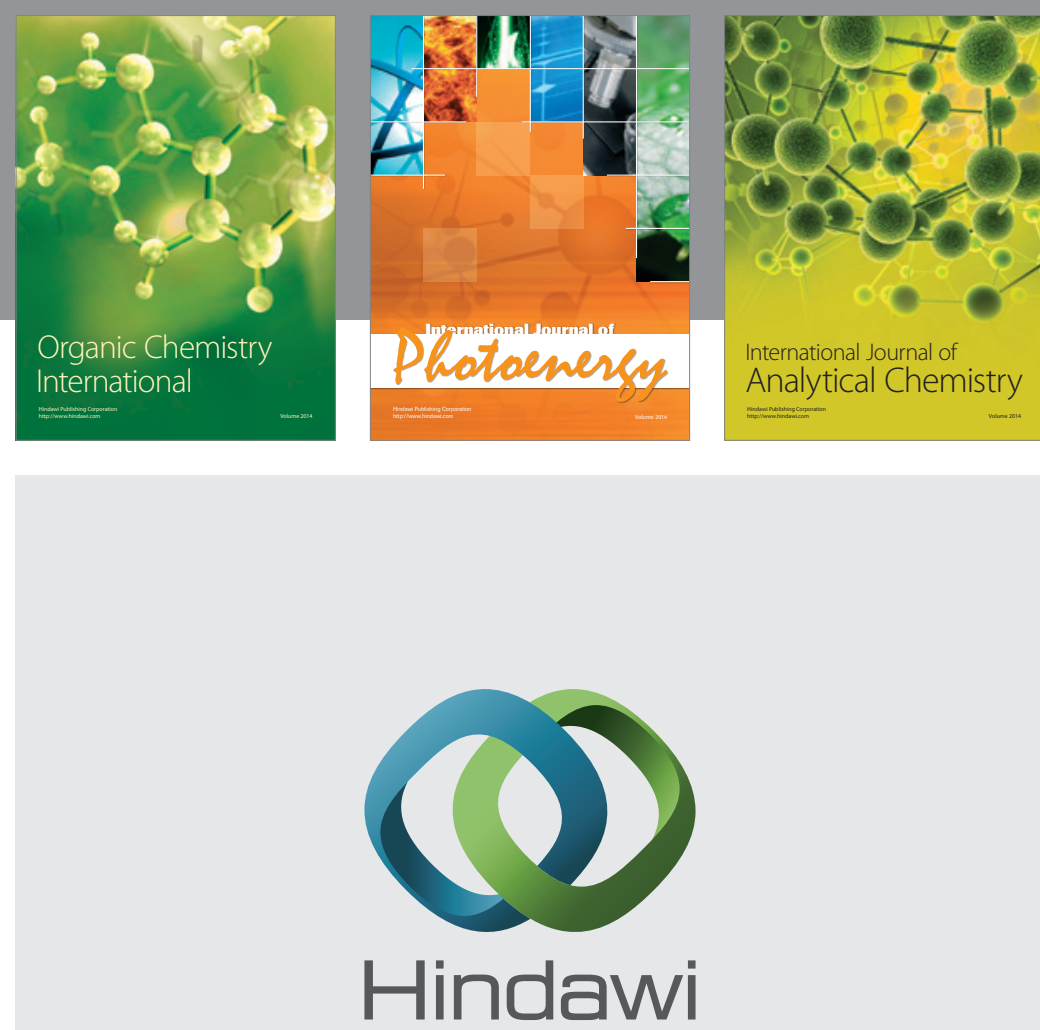

Submit your manuscripts at

http://www.hindawi.com
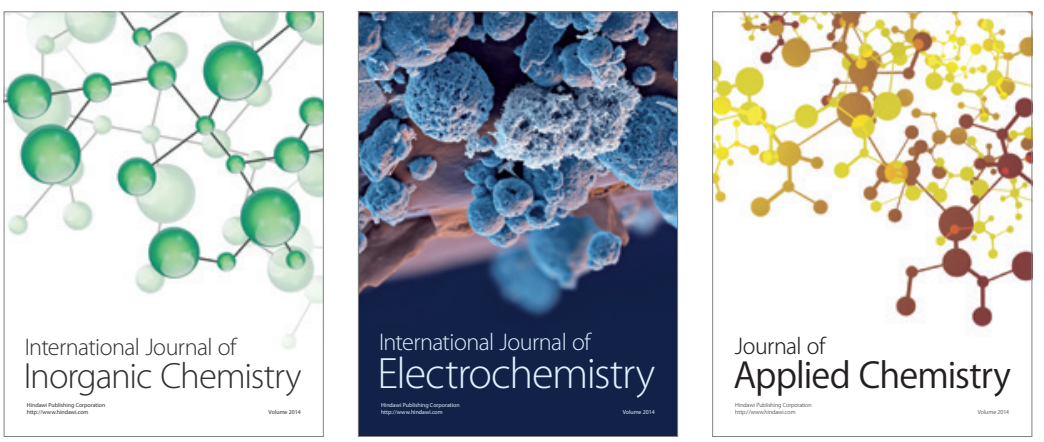

Journal of

Applied Chemistry
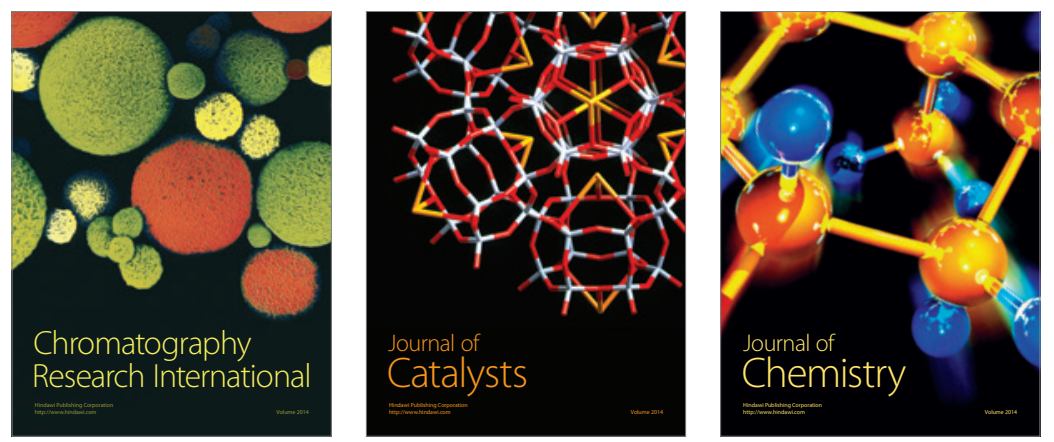
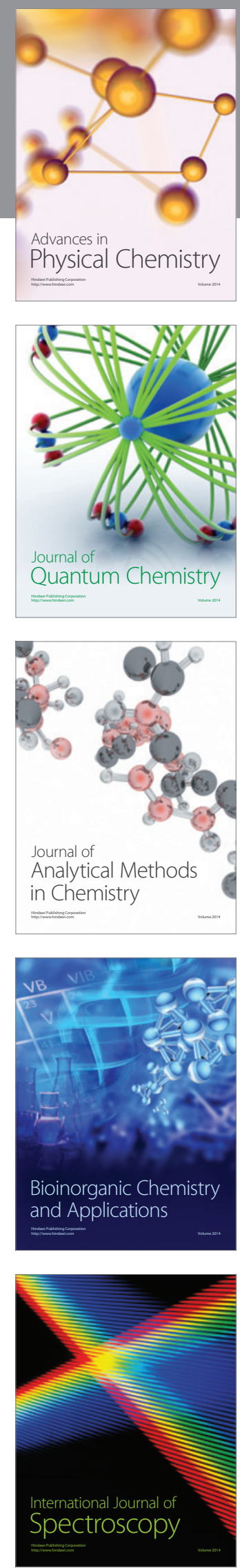